\title{
Intuition and inspiration made Gamow a star turn
}

\section{The astronomer's rare insight meant that his guesses were often surprisingly accurate.}

Sir-Horace Freeland Judson's forthright review of Genes, Girls and Gamow by James D. Watson (Nature 414, 775-776; 2001) reminds me that in the summer of 1953 , George Gamow did more than write to Watson suggesting how a linear sequence of four bases could result in different protein chains. He also delivered brilliant lectures at a now legendary astronomy summer school at the University of Michigan that I attended as his $\mathrm{PhD}$ student.

It is true that Gamow was funny and that he drank. It is also true that he was a brilliant scientist, devoted friend and concerned teacher, whose intuition exceeded that of any scientist I have known (see, for example, the Millennium Essay "The Big Bang and the genetic code" by Gino Segrè, Nature 404, 437; 2000).

Walter Baade, probably the greatest observational astronomer of the twentienth century, wrote in his book Evolution of Stars and Galaxies (Harvard University Press, 1963) the following: "I believe that George Gamow was the first to suggest the interpretation ... that is accepted today. ... Shortly after the publication of my paper on the two stellar populations, I received a typical message from Gamow on a postcard: 'Please tell me where the lower branch of the color-magnitude diagram joins the main sequence, and I will tell you the age of your Population II stars." When Baade replied that not enough data existed, Gamow promptly answered: "With due respect to Schoenberg and Chandrasekhar, I have extrapolated the lower branch thus. O.K. Four to five billion years.” Baade concludes: "This was a guess, of course, and that Gamow hit it so well was an accident, but his remarks really contained the whole story." Gamow's remarks often contained the whole story, and his guesses were often correct.

This correspondence is the second I have submitted to Nature. The first, sent about 30 years ago, was to protest about a job advertisement for a radio astronomer, which stated that "equally qualified women will be paid $x \%$ less than men", where $x$ was a number whose value (20?) I have forgotten. My contribution was not published because, the then-Editor wrote, in a year or so Australia was to put in place a law outlawing such discrimination.

Vera C. Rubin

Department of Terrestrial Magnetism, Carnegie Institution of Washington, 5241 Broad Branch Road NW, Washington, DC 20015, USA

\section{Postdocs don't need reality to hit so hard}

Sir - As a former French postdoc currently in 'exile' in England, mainly because of the depressing state of the current research system in France, I was outraged by Dr P.-L. Chau's Correspondence "Reality hits postdocs earlier in France" (Nature 414, 582; 2001) responding to your News article (Nature 414, 145; 2001). I can only assume that Chau is talking of another France, maybe on another planet, or that he mistakenly confuses the French tenured research system and the officially nonexistent (in terms of legal and social status) French postdoctoral system.

Postdocs in France are anything but civil servants, are typically at the mercy of their principal investigator, are often unable to conduct the research they want, and have to spend their time begging for short-term funding which, even if successful, barely supports a decent living. Of course one must not generalize, and progress is being made in improving the situation. But having experienced the system myself, and knowing numerous people who have suffered from it, or are still fighting to get a position in France, Chau's Correspondence is both erroneous and extremely depressing to all French postdocs.

Reality certainly hits the researcher earlier in France, but it couldn't hit any later than the $\mathrm{PhD}$ stage because by that time the person concerned is already working abroad.

Maryse Bailly

Division of Cell Biology, Institute of

Ophthalmology, University College London,

11-43 Bath Street, London EC1V 9EL, UK

\section{Talking about regeneration}

Sir - In your timely, engaging and well-illustrated News Feature "The regeneration gap" (Nature 414, 388-390; 2001), you report on the often-neglected invertebrate models of regeneration, such as planarians and hydra, and call for more attention to be paid to these invertebrates as models in the new field of regenerative medicine.

However, when referring to hydra and planarians, you describe stem cells as 'dormant' or 'mobilized when needed'. Actually, the reverse is true. These cells, called neoblasts in planarians, are continuously mobilized in young and adult worms (see J. Baguñà, E. Saló \& C. Auladell Development 107, 77-86; 1989). Many planarians do not regenerate or do so poorly while bearing neoblasts with normal rates of cell renewal. Therefore, neoblasts are not 'dormant' cells for regeneration, but function to replace differentiated cells lost during daily wear and tear.

This process of renewal speeds up during regeneration, while the rates to different cell lineages change to adapt to the axial pattern remodelling of the organism. Thus, terms such as 'dormant', 'reserve', or 'mobilized when needed' should be avoided when referring to stem cells in general and to planarian neoblasts in particular.

Jaume Baguñà

Departament de Genètica, Facultat de Biologia, Universitat de Barcelona, Diagonal 645, 08028 Barcelona, Spain

\section{Fruitful synthesis of science and fiction}

Sir — In his Words essay "Where might it lead?” (Nature 414, 399; 2001), Gregory Benford suggests how fiction can illuminate science. I agree that when a great writer weaves scientific concepts into his or her story, the reader is more likely to be drawn more deeply into the author's creation. I know of no other works of literature that marry the passions of science and unrequited love as eloquently as Umberto Eco's The Island of the Day Before.

Consider also some prose from Wallace Stegner's Pulitzer prizewinning 1971 novel Angle of Repose: "Many years later, when she reported that evening in her reminiscences, she was hearing the Doppler Effect of time, as I am now ... I think I hear the same tone, or tones, that she did: the sound of the future coming on for the girl of twenty-one, the darker sound of the past receding for the woman of eighty-four", and later, "now I, Ahab, dismasted and with tunnel vision, seeing the back of my own 
head through the curved lens of spacetime". One can ponder the parallels between the significance of the title of the book and the concept of 'angle of repose' in the theory of Per Bak and collaborators describing the self-organized critical state of complex systems.

As an illustration of Benford's assertion that fiction informs science, Peter Atkins's The Periodic Kingdom is required reading in my honours chemistry class, as is a creative writing assignment based on this book's format (necessarily fiction). Although it is initially perceived as an odd assignment, I hope to infect web-surfing, computergaming students with an appreciation for literary science and fiction.

Preston J. MacDougall

Department of Chemistry, Box X101, Middle Tennessee State University, Murfreesboro, Tennessee 37132, USA

\section{Standardizing chemical risk assessment, at last}

Sir - Industry is continually synthesizing new chemicals, the regulation of which requires evaluation of the potential danger for human health and the environment. Risk assessment is nowadays considered essential for making these decisions on a scientifically sound basis. Yet there are large data and conceptual gaps, which a new European Union (EU) white paper (policy document), Strategies for a Future Chemicals Policy (http://europa.eu.int/eur-lex/en/com/ wpr/2001/com2001_0088en01.pdf) is attempting to redress.

The white paper is intended to clarify the definition and quantification of 'risk'; the margins of safety for description as 'low risk' (which currently show large differences for pesticides, veterinary drugs and industrial chemicals); and acceptability criteria (currently, the same concentration of the same chemical in soil or food items can be regarded as low or high risk depending on the EU guideline applied!).

Terrestrial ecosystems are of particular concern. In the past, ecotoxicologists have for various reasons focused on aquatic systems, so terrestrial risk assessments have been forced simply to apply the aquatic model to soils, or have focused on specific targets such as risk posed by agrochemical pesticides to birds, bees and beneficial arthropods.

An example of this confusion is demonstrated by the risk assessment of an insecticide that has an acute earthworm toxicity of $1 \mathrm{mg}$ per $\mathrm{kg}$ (earthworm toxicity is a widely used measure, as earthworms are among the most sensitive soil-dwelling organisms). As things stand, such

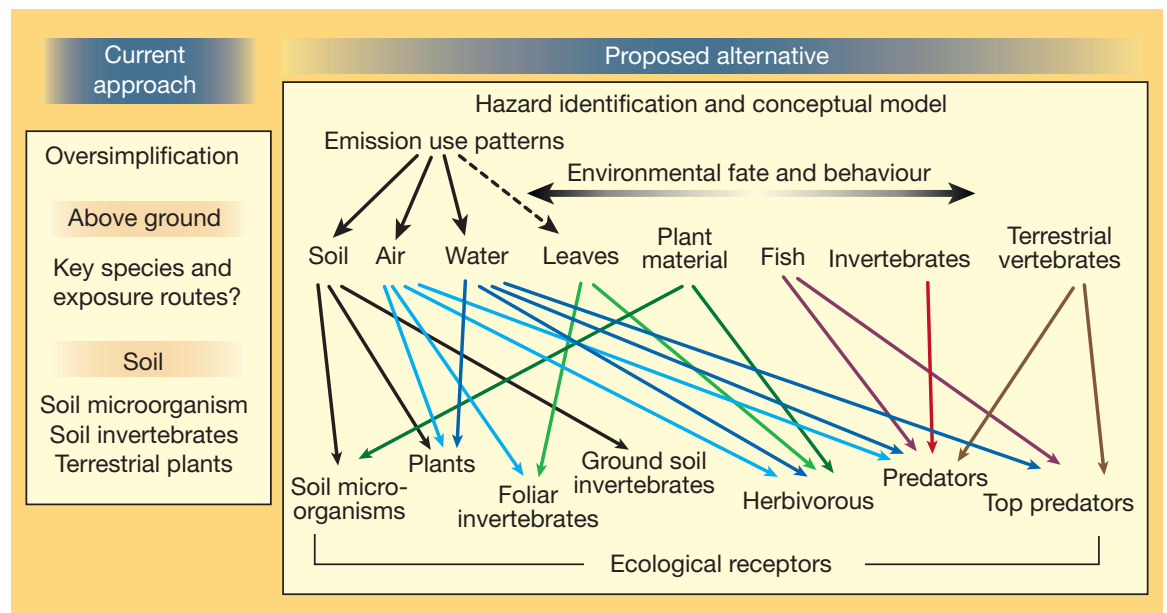

Comparison of the current and proposed approaches for the terrestrial ecological risk assessment of chemical substances.

assessments can simultaneously conclude that:

(1) A farmer can use the insecticide as a plant-protection product without risk for soil organisms if the concentration in the soil does not reach $0.1 \mathrm{mg}$ per $\mathrm{kg}$.

(2) The same farmer cannot use the insecticide as a veterinary medicine on farm animals if this use could produce concentrations in the same soil higher than $0.01 \mathrm{mg}$ per $\mathrm{kg}$.

(3) Industry-related processes (for example, use of sludge for fertilizer) giving concentrations higher than $0.001 \mathrm{mg}$ per $\mathrm{kg}$ in the same agricultural soil are classified as unacceptable risk, requiring risk refinement or risk reduction.

It is not clear whether confusing inconsistencies such as these originate from uncertainty, cost/benefit considerations, or the lack of scientific knowledge when the guidelines were set. Nevertheless, this inconsistency does not occur for aquatic risk assessment, where the rule is that a concentration 10 times below the chronic NOEC (highest concentration that does not produce effects) for the most sensitive aquatic species is acceptable. Any value above this trigger-point represents a potential risk.

Last year, the EU's Scientific Committee on Toxicology, Ecotoxicology and the Environment (CSTEE) reviewed the scientific basis of proper risk assessment on terrestrial ecosystems (http://europa.eu. int/comm/food/fs/sc/ sct/out83_en.pdf). The main weak points requiring further attention are the validation of model estimations with real monitoring data, and the development of a holistic approach for risk characterization. The new white paper requires much-needed simplified alternatives to speed up the assessment process. (At the current rate of progress, a comprehensive risk assessment of all chemicals currently on the market would take more than
1,000 years!). But, of course, simplifications should not jeopardize the best use of science. Now that the main research required to explore these alternatives has been identified by CSTEE, work can start, through the new EU chemicals strategy, while the Organisation for Economic Cooperation and Development and the United Nations Environment Programme can coordinate the extension of the approach beyond Europe.

We have compared the compartmentbased approach developed in the 1980s and 1990s with the more holistic view now proposed by the CSTEE (see figure). Instead of the traditional two-compartment approach, each covering three taxonomic groups, the new proposal is to select key route-receptor interactions for each assessment. Targeted protocols can be referred to specific emission or use patterns, particular exposure routes or specific ecological receptors, all of which offer a large potential for covering regulatory needs.

The conceptual model for terrestrial ecosystems proposed in the figure can be used to assess the risks to humans and other species of exposure to chemicals on agricultural and other managed systems, for biological agents such as foot-andmouth disease and bovine spongiform encephalopathy, and even radiation.

\section{J. V. Tarazona}

Spanish National Institute for Agriculture and Food Research and Technology (INIA), Carretera de La Coruña km 7, 28040 Madrid, Spain

Other signatories to this letter and members of the CSTEE Terrestrial Working Group:

K. Hund Fraunhofer Institute for Environmental Chemistry and

Ecotoxicology, Germany

T. Jager National Institute of Public Health and the Environment (RIVM), The Netherlands

M. S-Salonen University of Helsinki, Finland

A. M. V. M. Soares University of Aveiro, Portugal

J. U. Skaare National Veterinary Institute, Norway

M. Vighi University of Milano-Bicocca, Italy 